\title{
Fundamental issues of reactive wetting by liquid metals
}

\author{
O. Dezellus ${ }^{1}$, N. Eustathopoulos ${ }^{2}$
}

\author{
${ }^{1}$ LMI - UMR CNRS 5615
}

University Lyon 1, 43 Bd du 11 novembre 1918, 69100 Villeurbanne, France

Tel.: $+33-472438386$

Fax: $+33-472440618$

olivier.dezellus@univ-lyon1.fr

${ }^{2}$ SIMAP - UMR CNRS 5615

INP - Grenoble, 1130 rue de la Piscine, 38042 St Martin d'Hères, France

\begin{abstract}
After a brief presentation of thermodynamics and kinetics of non-reactive wetting, the recent results and theoretical developments concerning the reactive wetting of solids by liquid metals are reviewed. A section is devoted to illustrate and discuss the effect of interfacial reactions in removing the wetting barriers existing on many ceramic and metallic solids.
\end{abstract}

\section{Introduction}

This review concerns the wetting of high temperature solids, mainly ceramics, by liquid metals and alloys. Many metal/ceramic couples are far from equilibrium and the resulting interfacial reactions can strongly modify the chemistry, structure and topography of the contact area .These changes affect both spreading kinetics and the ultimate degree of wetting and those aspects of reactive wetting that can be exploited in practice to control wetting and adhesion are reviewed in this paper.

The paper is organized in three parts. In section 1 the main features of non-reactive wetting of metals on various types of solids are rapidly presented. The main part of the paper (section 2) is on thermodynamics and kinetics of reactive wetting. After briefly describing the basic aspects of the "Reaction Product Control" model, recent results and developments of this model are given in more detail. In a final section the role of interfacial reactions in the 
removal of wetting barriers existing on many metallic and ceramic solids is illustrated with several examples.

\section{1 - Non-reactive wetting}

\subsection{Thermodynamics}

As a general rule, the interaction energy between a liquid and a solid substrate is quantified by the work of adhesion $W_{a}$ related to the characteristic surface energies $\sigma_{i j}$ of the solid (S)liquid (L)-vapour (V) system by the Dupré equation:

$$
W_{a}=\sigma_{S V}+\sigma_{L V}-\sigma_{S L}
$$

Combining this expression with Young's equation $\cos \theta=\frac{\sigma_{S V}-\sigma_{S L}}{\sigma_{L V}}$

leads to the following fundamental equation of wetting, known as the Young-Dupré equation:

$$
\cos \theta=\frac{W_{a}}{\sigma_{L V}}-1
$$

This equation shows that the equilibrium contact angle obtained for a given liquid metal on a solid substrate results from the competition of two types of forces: adhesion forces that develop between the liquid and solid phases, expressed by $W_{a}$ (tending to increase the common area thus improving wetting), and cohesion forces of the liquid taken into account by the surface energy of the liquid $\sigma_{L V}$ acting in the opposite direction (the cohesion energy of the liquid is roughly equal to $2 \sigma_{L V}$ ). Liquid metals are high cohesion energy liquids indeed their cohesion energy at melting point represents more than $90 \%$ of the cohesion energy of the same metal in the solid state. Thus, according to the Young-Dupré equation, good wetting of a liquid metal on a solid substrate, i.e a $\cos \theta$ close to unity, can be obtained only if the work of adhesion is also high, which is possible if the interfacial bond is strong, i.e. chemical. 
Table 1: Wetting by non-reactive liquid metals

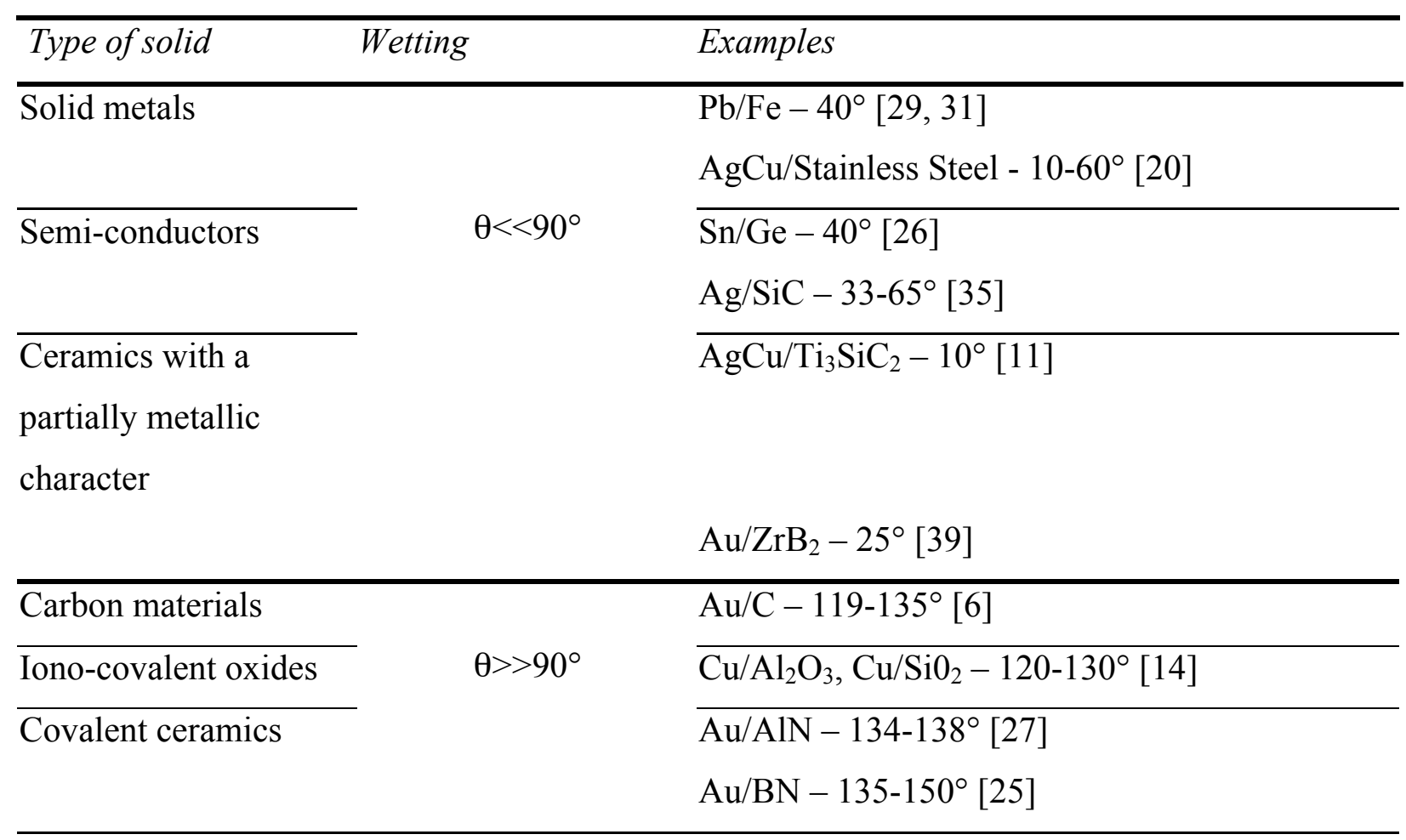

For this reason good wetting is the general rule for liquid metals on solid metals whatever the intensity of interaction between liquid and solid, the interfacial bond being metallic, i.e. strong (see table 1). Liquid metals also wet semi-conductors such as $\mathrm{Si}, \mathrm{Ge}$ or $\mathrm{SiC}[26,30,35]$ because the cohesion of semi-conductors has a metallic character near the free surface. Finally, liquid metals also wet ceramics such as carbides, nitrides or borides of transition metals because a significant part of the cohesion of these materials is provided by metallic bonds $[11,39]$. Solids that are not wetted by non-reactive liquid metals include the different forms of carbon [6], iono-covalent oxides and covalent ceramics with a high band gap such as $\mathrm{BN}$ or $\mathrm{AlN}[25,27]$.

It should be emphasized that, even with wettable solids, contact angle values less than $90^{\circ}$ can be prevented by the presence of wetting barriers on the solid surface. Thus, many of the ceramics with a partially metallic character (such as borides of transition metals), some covalent ceramics (such as $\mathrm{SiC}$ and $\mathrm{Si}_{3} \mathrm{~N}_{4}$ ) and many metallic solids (stainless steels, superalloys, Al containing alloys...) are also easily oxidized and their wettability by nonreactive metals is strongly affected by oxide films that may be very tenacious, especially at low temperatures $[11,31,33]$. 


\subsection{Spreading kinetics}

In non-reactive systems, the spreading rate is controlled by the viscous flow and described by a power function of the triple line velocity $U$ vs. the instantaneous contact angle $\theta$

$$
U \sim \theta^{n}
$$

For a spherical shaped drop with a base radius $\mathrm{R}, \mathrm{U}=\mathrm{dR} / \mathrm{dt}$ and equation 3 a leads to

$$
\mathrm{R}^{3 \mathrm{n}+1} \sim \mathrm{t}
$$

De Gennes has developed an analytical approach in which the spreading rate is considered to be limited by the viscous dissipation in the drop bulk leading to $n=3$ [4], while Blake's model, which is based on dissipation at atomic level at the triple line, leads to $n=2$ [1]. Because the viscosity of molten metals is very low, the spreading time (i.e. the time needed for millimetric size droplets to reach capillary equilibrium) is less than $10^{-1} \mathrm{~s}$ in the case of non-reactive systems with equilibrium contact angle values higher than $20^{\circ}[26,30,37,43]$. A significantly longer spreading time was observed in [21] for a couple with an equilibrium contact angle very close to zero.

\section{2 - Reactive wetting}

In 1996 Landry proposed a model to describe wetting for metal/ceramic systems in which the interfacial reactions lead to the formation of continuous layers of a new compound [22]. According to the model ("reaction product control" model), both the final contact angle and spreading kinetics are governed by the interfacial reaction. Note that in 2000, Saiz et al. [36] suggested that reactive wetting is caused mainly by adsorption, while spreading kinetics is controlled by the migration of a ridge formed at the solid-liquid-vapour triple line. In 2005 [13] a detailed analysis of existing experimental data was published that did not confirm the Saiz et al. approach. Since that date no new results or new developments concerning this approach have been published and for this reason the approach of Saiz et al. is not reported in the present review.

\section{2-1 Reactive vs non-reactive wetting}

Recently, Bougiouri et al. illustrated the first-order transition, from the point of view of wetting, that is associated with the non-reactive to reactive transition in the case of $\mathrm{Ni}-\mathrm{Si}$ 
alloys on vitreous carbon $\left(C_{v}\right)$ substrates [2]: when the silicon content in the liquid alloy is below the minimum silicon content needed for $\mathrm{SiC}$ formation $\left(35 \mathrm{at} \%\right.$ at $\left.1200^{\circ} \mathrm{C}\right)$, no $\mathrm{SiC}$ is indeed formed at the liquid/solid interface and the system is characterized by a high contact angle value $\left(123^{\circ}\right)$. Conversely, when the $\mathrm{Si}$ content exceeds the reactivity limit, a thin continuous $\mathrm{SiC}$ layer is formed along the whole interface leading to spreading of the liquid alloy. The continuous layer is revealed for example by the triple line receding during cooling after capillary equilibrium is reached (see Fig. 1).

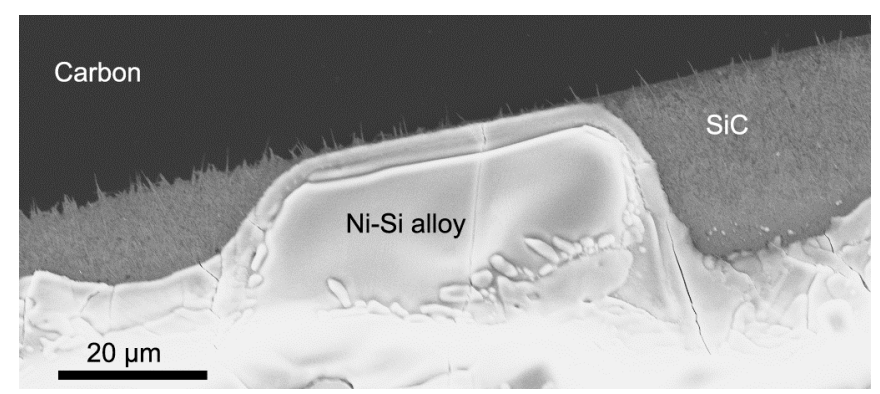

Fig. 1: SEM image of a triple line region of a Ni-66.8 at\% Si alloy on $C_{v}$ observed from above. X-ray micro-analysis of area exposed after receding reveals the presence of $\mathrm{C}$ and $\mathrm{Si}$ only [2]

Moreover, the authors compared the work of immersion $\left(W_{i}=\sigma_{S L}-\sigma_{S V}=-\sigma_{L V} \cdot \cos \theta\right)$ obtained with the same Ni-Si alloys either in the reactive case on carbon, or in the nonreactive case on $\mathrm{SiC}$ substrates (see Fig. 2). It appears clearly that both values, on $\mathrm{C}$ and $\mathrm{SiC}$ substrates, lie on the same curve. This quantitative agreement clearly indicates that the nonwetting to wetting transition observed between non-reactive and reactive alloys is due to the replacement of vitreous carbon by wettable $\mathrm{SiC}$ at the interface. 


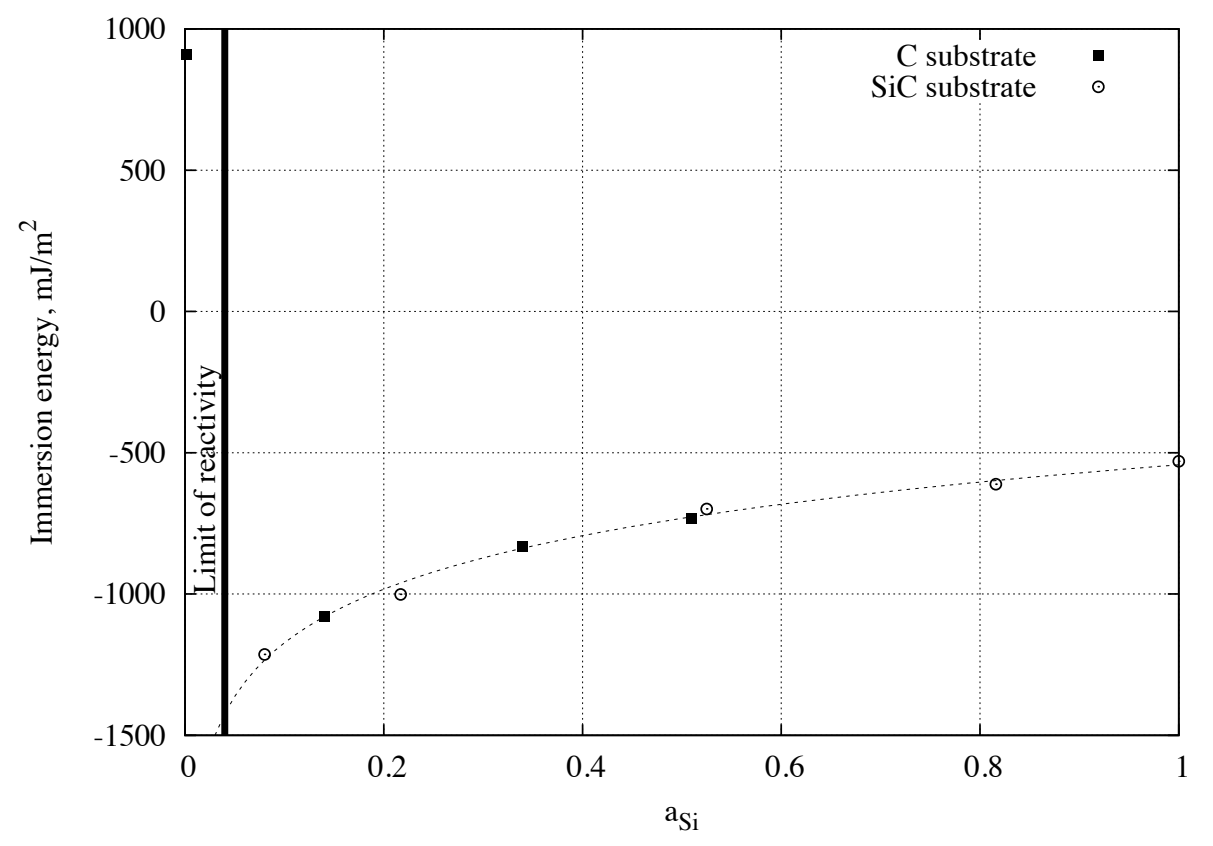

Fig. 2: Immersion energy $W_{i}=\sigma_{S L}-\sigma_{S V}$ vs Si activity of NiSi alloys on $C_{v}$ (squares, [2]) and on $\mathrm{SiC}$ (circles, [34]). $\mathrm{T}=1200^{\circ}$. The reactivity limit for the $C_{v}$ substrate is shown by the dotted line.

\subsection{Spreading kinetics}

The spreading time observed for reactive metal/ceramic systems, where a new compound is formed at the interface during spreading, is in the range $10^{1}-10^{4} \mathrm{~s}$, i.e. several orders of magnitude higher than for non-reactive systems. As a consequence, the spreading rate in reactive systems is not limited by viscous dissipation but by the rate of interfacial reaction at the triple line [22]. In turn, this rate is controlled by the slower of two successive phenomena that take place in the reaction process: diffusive transport of reacting species to or from the triple line and local reaction kinetics at the triple line.

\section{Control by the local reaction at the triple line}

In the case of control by the local reaction at the triple line, the rate of reaction and hence the triple line velocity are expected to be constant with time [22]. Since the first experimental evidence obtained for unalloyed aluminium on carbon [22], constant or nearly constant triple line velocities $U$ have been observed for different systems such as the $\mathrm{CuSi} / \mathrm{C}$ [7] and NiSi/C [2] systems, for CuSi alloys on oxidized $\mathrm{SiC}$ [10] , for pure $\mathrm{Si}$ on oxidized $\mathrm{Si}_{3} \mathrm{~N}_{4}$ [12] and for Ti-containing Ni-based alloys on AIN [19]. An example is given in Fig. 3 for a NiSi alloy on vitreous carbon. After transient spreading, where the contact angle decreases in a few tens of 
seconds from $160^{\circ}$ to $110^{\circ}$, the spreading rate $\mathrm{dR} / \mathrm{dt}$ continues to decrease but only slightly ("quasilinear spreading") and tends towards a constant value $\mathrm{U}^{*}$ when $\theta$ tends towards $\theta_{\mathrm{N}}$. The quasilinear spreading proves that the spreading rate is not limited by long-range diffusion of the reactive element $(\mathrm{Si})$ but by the local reaction process at the triple line. At $\theta=\theta_{\mathrm{N}}$ a second wetting stage appears abruptly, accompanied by a net decrease in spreading rate. This stage is discussed later.

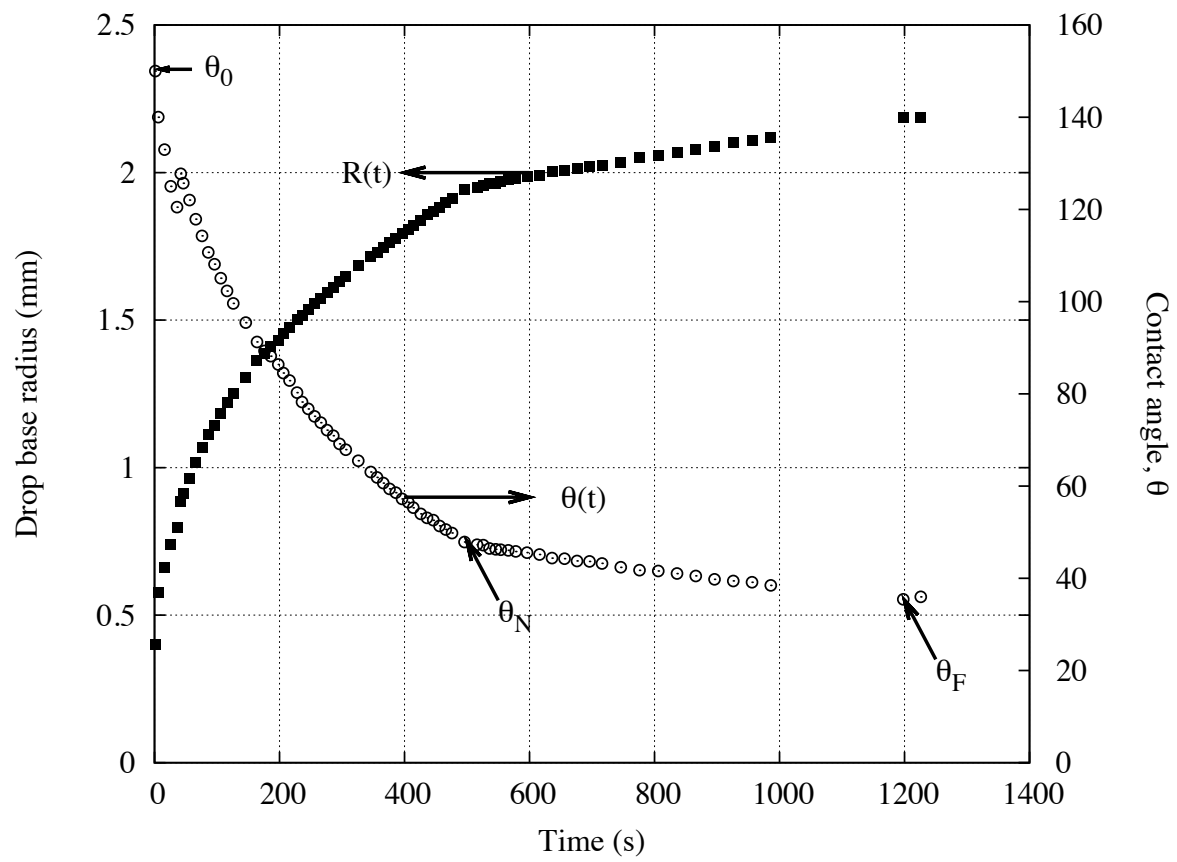

Fig. 3: Typical change in drop base radius $R$ and contact angle $\theta$ with time in the case of reactive spreading kinetics limited by the local process at the triple line. Ni-63 at.\%Si alloy on vitreous carbon at $1200^{\circ} \mathrm{C}[2]$.

For the quasilinear stage, a model leading to analytical expressions of contact angle as a function of time, has been developed [7, 8] assuming that, at any time, the instantaneous contact angle $\theta$ reflects the local chemistry of the interface at the triple line (referred to hereafter as TL) where the interface is composite, partly of the liquid/initial substrate type and partly of the liquid/reaction product type. Moreover the reaction rate is assumed to be controlled by the dissolution process, i.e., by the process of atom transfer occurring at the substrate/alloy interface.

The following equations describing spreading were derived for the change in contact angle with time t: 


$$
\cos \theta_{F}-\cos \theta=\left(\cos \theta_{F}-\cos \theta_{0}\right) \cdot \exp (-k . t)
$$

And for the dependence of the spreading rate $U$ on the instantaneous contact angle $\theta$ :

$$
\frac{U}{F(\theta)}=k \cdot\left(\frac{3 V}{\pi}\right)^{1 / 3} \cdot\left(\cos \theta_{F}-\cos \theta\right)
$$

with $F(\theta)=-\frac{\cos \theta \cdot\left(2-3 \cdot \cos \theta+\cos ^{3} \theta\right)-\sin ^{4} \theta}{\sin \theta \cdot\left(2-3 \cdot \cos \theta+\cos ^{3} \theta\right)^{4 / 3}}$ and $\mathrm{V}$ being the volume of the liquid droplet.

The constant $k$ in Eqs. 4 and 5 is proportional to the kinetic constant $k_{d}$ and to the driving force $\Delta \mu$ of the dissolution process. For the NiSi/C system, $\Delta \mu$ is the difference between the chemical potential of carbon in the solid and the liquid and is related to the activity of $\mathrm{Si}$ in the alloy $a_{S i}$ by the equation 6 :

$$
\Delta \mu=R T \cdot \ln \frac{a_{S i}}{a_{S i}^{I}}
$$

where $a_{S i}{ }^{\mathrm{I}}$ is the minimum value of $\mathrm{Si}$ activity for $\mathrm{SiC}$ formation by reaction between $\mathrm{Si}$ in the alloy and solid carbon $\left(a_{S i}{ }^{\mathrm{I}}\right.$ corresponds to the equilibrium of three phases: initial substrate, reaction product and liquid).

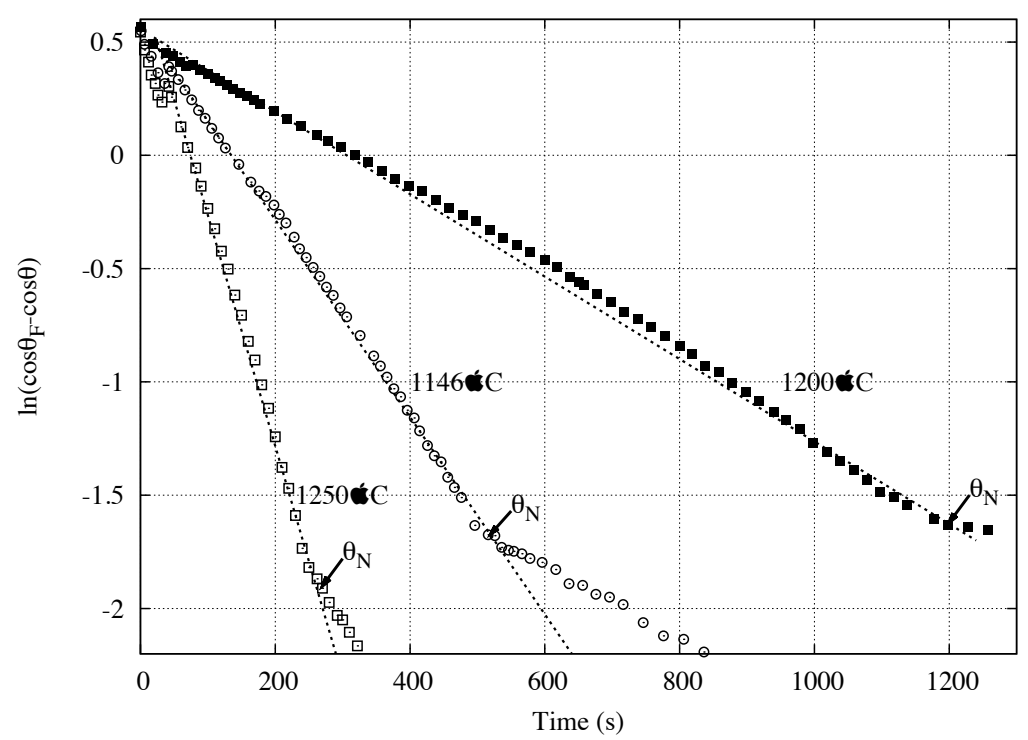

Fig. 4: Natural logarithm of $\cos \theta_{F}-\cos \theta$ versus time $t$ for $\mathrm{Ni}-63$ at. $\% \mathrm{Si}$ alloy/C ${ }_{v}$ system at different temperatures [7]. 
According to this expression logarithmic plots of $\cos \theta_{F}-\cos \theta$ versus time would be linear with a slope equal to minus $k$. An example is given in figure 4 for Ni-63 at.\% Si alloy on vitreous carbon at different temperatures. The experimental data agree with the linearity predictions in a wide domain of theta. The sharp change in the slope of straight lines reflects the high value of the activation energy of the dissolution process (about $250 \mathrm{~kJ} \mathrm{~mol}^{-1}$ in this case) [2]. For dissolution reactions controlled by the atomic process at the interface, the kinetic constant $k_{d}$ is in principle sensitive to the crystallographic structure of the initial substrate. This is confirmed by the strong variation in the triple line velocities observed for $\mathrm{Cu}-50 \mathrm{at} . \% \mathrm{Si}$ on two different types of carbon: vitreous carbon and pseudo-monocrystalline graphite (Fig. 5).

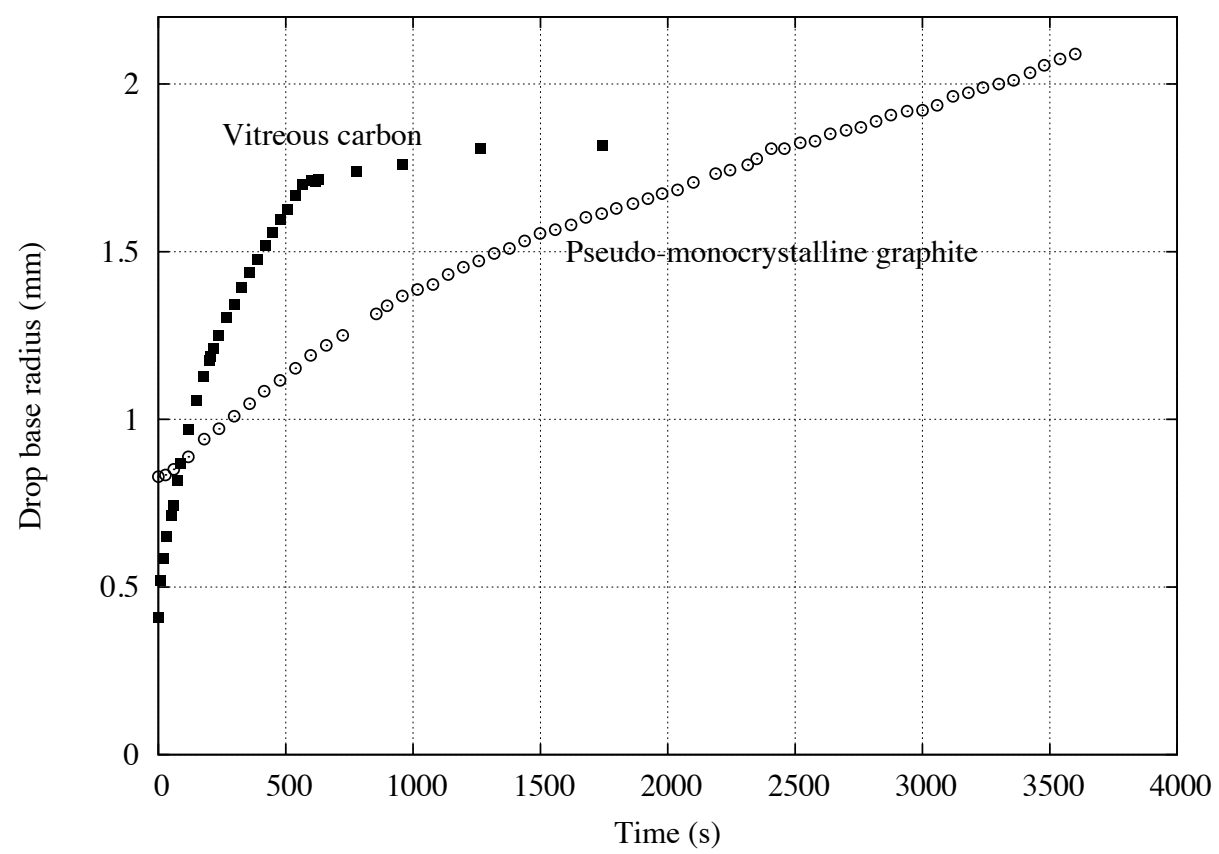

Fig. 5: Change in drop base radius versus time $\mathrm{t}$ for $\mathrm{Cu}-50$ at.\% $\mathrm{Si}$ alloy on two different types of carbon: vitreous carbon and pseudo-monocrystalline graphite at $1200^{\circ} \mathrm{C} \mathrm{[5].}$

As for the influence of the activity of reactive element on spreading kinetics, according to Eq. 6 this would be weak, in agreement with experimental findings [3]. According to Eq. 5, plots of the spreading rate $U$ divided by $F(\theta)$ versus the cosine of the instantaneous contact angle would be linear. This was verified by the results of Muolo et al. [24] for the CuAg-5at\%Ti alloy on three different substrates, two oxidic (an alumina-zirconia ceramic and zirconia stabilized by yttria) and one metallic (the superalloy Inconel 738). 
Control by local reaction at the triple line: strong vs weak coupling

Fig. 3 shows that the spreading rate changes abruptly at a contact angle noted $\theta_{\mathrm{N}}$. As discussed in detail elsewhere [5], this reflects the change in the microscopic configuration at TL. At $t<t_{N}\left(\theta>\theta_{N}\right)$ direct contact between the liquid and the initial substrate results in a high dissolution rate and in a strong coupling between the local chemical reaction and spreading kinetics. The microstructure of the reaction product in this stage is columnar $[3,7]$ At $t>t_{N}$ the liquid no longer has direct access to the initial substrate surface and a slow reaction takes place by nucleation and growth of reaction product particles occurring on the substrate free surface in front of TL (see Fig. 6 for schematic description of TL configuration). Direct experimental evidence for this mechanism, which leads to formation of an equiaxial microstructure, was given recently in [3] (see Fig. 7). Table 2 reports the main features of the two wetting stages. The last column gives the growth rate of the reaction layer on the carbon free surface once the capillary equilibrium was attained (in this case the reaction front advances while TL does not move). The comparison indicates that the rate of the linear spreading stage is much closer to the growth rate of silicon carbide during the decoupled growth than to the TL velocity in the quasilinear stage. 

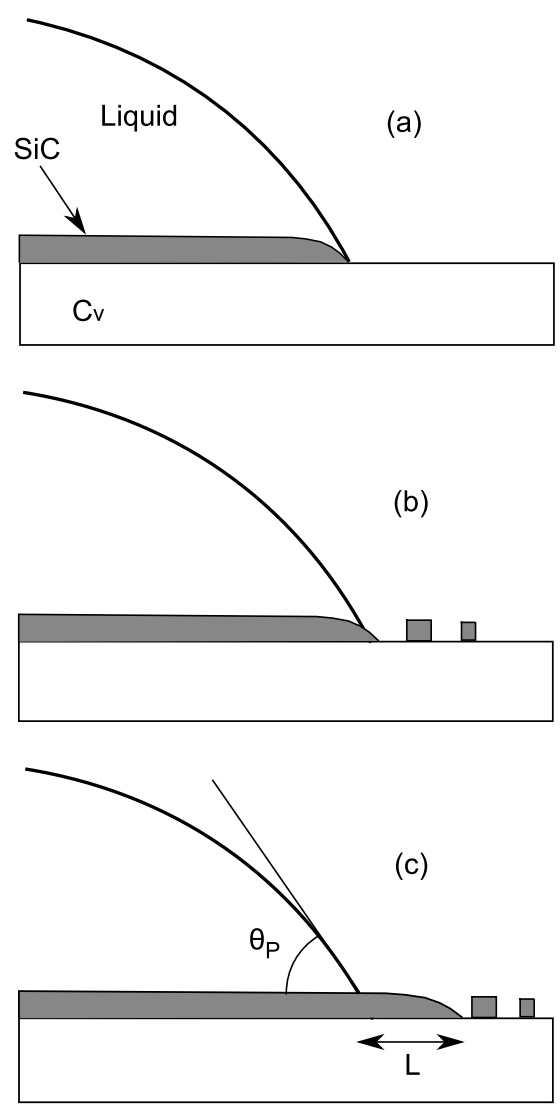

Fig. 6: Schematic representation of the configuration at the triple line (a) at $\theta>\theta_{N}$, direct contact between the liquid and initial substrate leads to strong coupling between the local chemical reaction and spreading kinetics. (b) at $\theta<\theta_{\mathrm{N}}$, the liquid no longer has direct access to the initial substrate surface and coupling is weak, (c) when $\theta_{\mathrm{P}}$ is reached, decoupled growth of reaction product ahead of TL occurs .(according to [5])

Table 2: Wetting of vitreous carbon by $\mathrm{Cu}-50$ at. $\% \mathrm{Si}$ at $\mathrm{T}=1200^{\circ} \mathrm{C}$. Characteristics of the three different regimes [5]

\begin{tabular}{l|c|c|c}
\hline \multicolumn{1}{|c|}{ Regime } & $\theta>\theta_{N}$ & $\theta_{P}<\theta<\theta_{N}$ & $\theta=\theta_{P}$ \\
\hline $\mathrm{R}(\mathrm{t})$ law & quasilinear & linear & - \\
\hline $\mathrm{U}(\mathrm{nm} / \mathrm{s})$ & $630^{*}$ & $54^{*}$ & $20^{* *}$ \\
\hline Activation energy $(\mathrm{kJ} / \mathrm{mol})$ & $255 \pm 30$ & $335 \pm 15$ & - \\
\hline Microstructure & columnar & equiaxial & equiaxial \\
\hline
\end{tabular}

* At $\theta=\theta_{\mathrm{N}}$

** Average value, $\mathrm{L}=30 \mu \mathrm{m}, \Delta \mathrm{t}=1500 \mathrm{~s}$ 

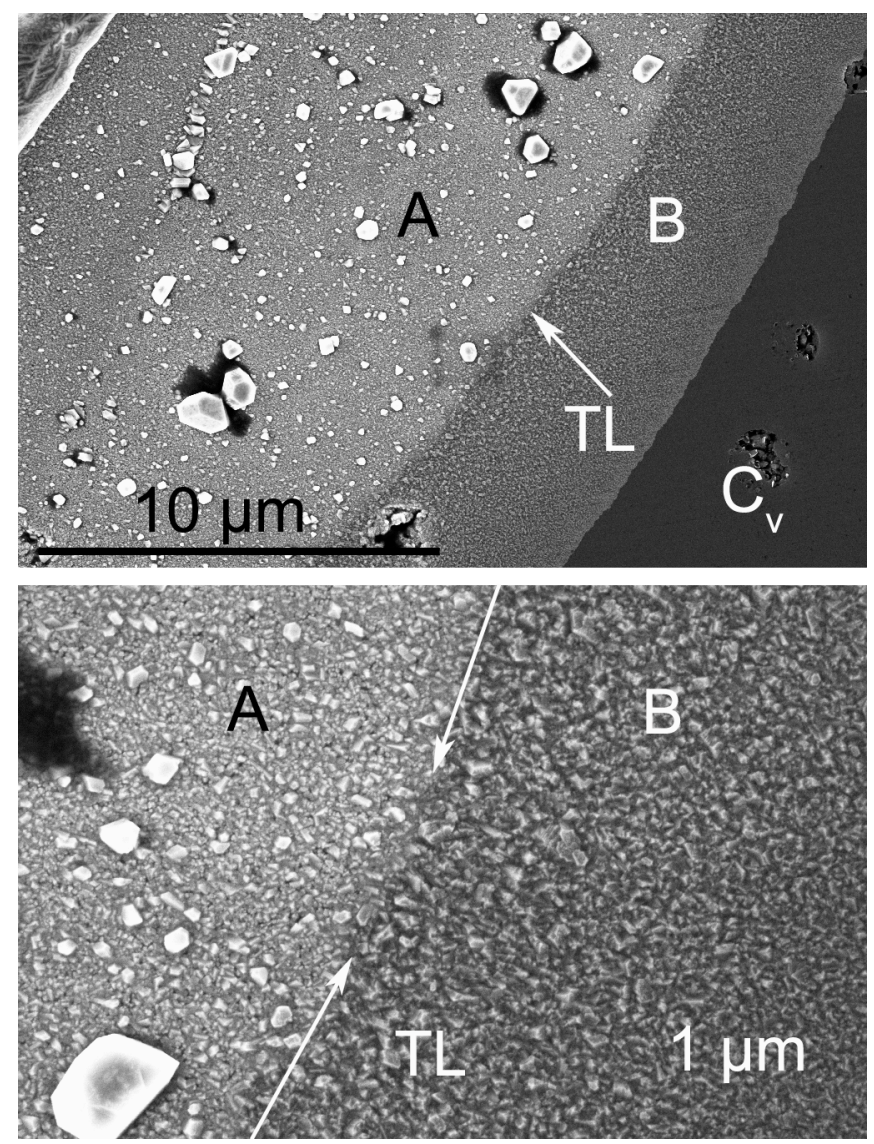

Fig. 7: Top view of the reaction layers close to the triple line for Al-25at.\% $\% \mathrm{Si} / \mathrm{C}_{\mathrm{v}}$.Zone A (observed after removing, by dissolution, the Al-Si alloy) corresponds to $\mathrm{SiC}$ formed during weakly coupled spreading $\left(\theta_{P}<\theta<\theta_{N}\right)$, while zone B corresponds to the growth of a film ahead of the TL after capillary equilibrium is reached $\left(\theta=\theta_{P}\right)[3]$.

\section{Diffusion-controlled reactive wetting}

Diffusion-controlled wetting was modelled by Mortensen et al. in 1997 [23]. According to this model, the rate of isothermal spreading $U=\frac{d R}{d t}$ is time-dependent and varies in direct proportion to the instantaneous contact angle $\theta$.:

$$
\frac{d R}{d t}=\frac{2 \cdot D \cdot F(t)}{e \cdot n_{v}} \cdot\left(C_{0}-C_{e}\right) \cdot \theta
$$


where $\mathrm{D}$ is the diffusion coefficient in the liquid, $\mathrm{n}_{\mathrm{v}}$ is the number of moles of reactive solute per unit volume of the reaction product, $\mathrm{e}$ is the reaction product thickness at the triple line, $\mathrm{C}_{0}$ is the nominal (far-field) drop reactive solute concentration, $\mathrm{C}_{\mathrm{e}}$ is the concentration of reactive solute in equilibrium with the reaction product (such that $\mathrm{C}=\mathrm{C}_{\mathrm{e}}$ at the triple line). $\mathrm{F}(\mathrm{t})$ is strictly a function of time but in fact varies so little that it can be taken to be constant, remaining close to 0.04 in usual sessile drop experiments [23].

When compared with experimental results, this relation shows good agreement for systems such as $\mathrm{CuSn}-\mathrm{Ti} / C_{v}[9]$, in which the final contact angle is close to zero. However some discrepancies remain in other cases such as $\mathrm{Cu}-\mathrm{Cr} / C_{v}$. For this system the intercept of the line giving $\frac{d R}{d t}$ vs. $\theta$ with the $\theta$-axis is not at the origin $(\theta=0)$, but rather at a finite angle close to $40^{\circ}$ [38] as shown in Fig. 8. Note that the Mortensen equation was established by assuming that all solute flux is consumed by the reaction at the triple line, thus neglecting any thickening of the reaction layer behind the triple line. However, this assumption is hardly verified in the $\mathrm{Cu}-\mathrm{Cr} / C_{v}$ system, where chromium carbide interfacial reaction layers are relatively thick (several micrometers) and continue to thicken if the drop is held at temperature, indicating rapid carbide growth kinetics in this system.



Fig. 8: Experimental triple line velocity as a function of instantaneous contact angle $\theta$ for $\mathrm{Cu}-$ 1 at.\% $\mathrm{Cr}$ on vitreous carbon at $1150^{\circ} \mathrm{C}[38]$ and spreading rate according to Mortensen's model [23] 
To verify the effect of thickening on the spreading kinetics, numerical calculations of the wetting process by finite element modelling was recently performed in the case of $\mathrm{Cu}-\mathrm{Cr}$ alloy on $C_{v}$ [16]. Calculations were performed by arbitrarily varying the value of the diffusion coefficient $D_{C}$ of $\mathrm{C}$ in chromium carbide. It was found that for very low values of $D_{C}$ the rate of reaction product growth behind the triple line is negligible. The triple line velocity is then simply proportional to the instantaneous contact angle $\theta$, as predicted by Mortensen's analytical model. When $D_{C}$ increases, the curve giving the triple line velocity $\mathrm{U}$ as a function of $\theta$ remains linear, retaining the same slope, but is shifted so that its intercept with the $\theta$-axis increases progressively. Finally, the experimental data are relatively well predicted for $D_{C}$ equal to $6.10^{-15} \mathrm{~m}^{2} \mathrm{~s}^{-1}$ which is a realistic value for this system.

As a conclusion, the simulation yields the following general result: interfacial reactivity manifests itself by the presence of a finite "dead-angle" that must be subtracted from $\theta$ in Mortensen's analytical solution, this equation remaining otherwise essentially valid. The physical meaning of the dead angle is presented on Fig. 9: the flux across the solid angle delimited by the "dead angle" is deviated away from the TL and consumed in thickening of the reaction layer behind the TL.

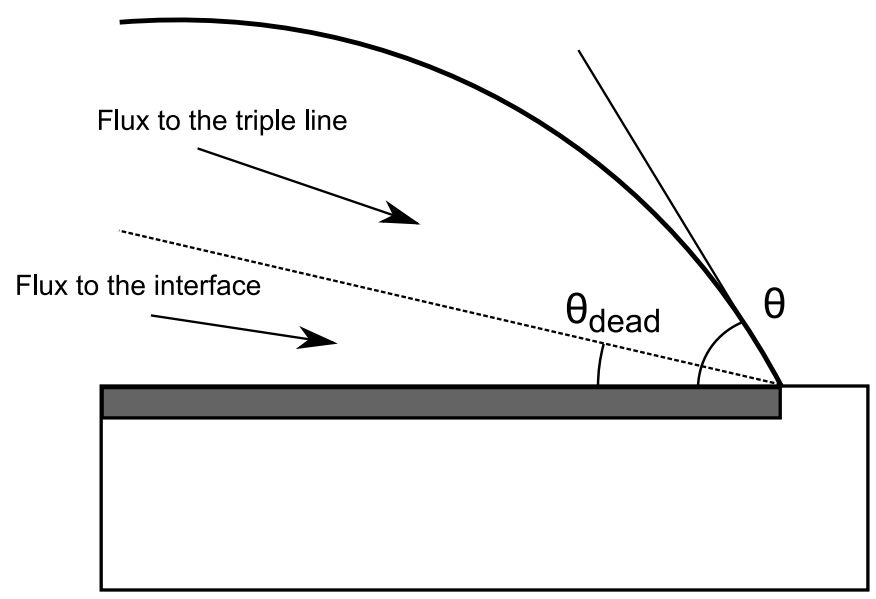

Fig. 9: Schematic representation of the physical meaning of the dead angle that must be subtracted from $\theta$ in Mortensen's analytical solution (Eq. 7). The flux across the solid angle delimited by the "dead angle" is deviated away from the TL and consumed in thickening of the reaction layer behind the TL. 


\section{3 - Interfacial reactions vs wetting barriers}

Most of the non-oxide ceramics are easily oxidized and the oxide films on their surface act as wetting barriers leading to non-wetting by non-reactive liquid metals. Reactivity at liquid/solid interfaces can remove these wetting barriers thus improving wetting. Symmetrically, reactivity can also lead to the formation of a reaction product less wetted than the initial substrate, i.e to the formation of a wetting barrier.

An interesting example was given by Frage et al. in the Au-TiC system [15]. The authors showed that pure $\mathrm{Au}$ does not wet $\mathrm{TiC}$ the contact angle being about $130^{\circ}$ a value that is similar to that obtained for Au on carbon substrates (see Table 1). Because of the strong interaction between $\mathrm{Au}$ and $\mathrm{Ti}$ slight dissolution of $\mathrm{Ti}$ from the substrate into the liquid occurs. However, as the solubility of $\mathrm{C}$ in $\mathrm{Au}$ is much smaller than that of $\mathrm{Ti}$, graphite precipitates at the interface leading to a contact angle of $130^{\circ}$ which is characteristic of $\mathrm{Au}$ on graphite (Table 1). A similar case where reactivity leads to the formation of a wetting barrier was already reported by Kalogeropoulou et al. in the $\mathrm{Ag} / \mathrm{SiC}$ system [17] where dissolution of $\mathrm{Si}$ in the melt leads to precipitation of graphite at the liquid/solid interface. As for the $\mathrm{Au} / \mathrm{TiC}$ system, Frage et al. performed some additional experiments with Au containing different alloying elements. The solubility of $\mathrm{C}$ in molten Ni being several orders of magnitude higher than in $\mathrm{Au}$, small Ni additions increase the solubility of $\mathrm{C}$ significantly, thereby preventing the formation of the graphite layer on the $\mathrm{TiC}$ substrate. In this case, the experimental results show a dramatic decrease in contact angle towards values in the range $60^{\circ}-80^{\circ}$ for 3 to 7 at. $\%$ of Ni (see Fig. 10) without any reaction product at the interface. In this system, the action of $\mathrm{Ni}$ is to remove the wetting barrier by dissolution.



Fig. 10: Contact angle between stoichiometric $\mathrm{TiC}$ and $\mathrm{Au}$ alloys at $1150^{\circ}$ [15] 
Silicon carbide is a typical example of non-oxide ceramic that is easily oxidized. Indeed even under high vacuum $\mathrm{SiC}$ surfaces at temperatures less than $1100^{\circ} \mathrm{C}$ are usually covered by a silica film that acts as a wetting barrier. However, with alloys containing $\mathrm{Si}$, the removal of silica is possible by the formation of the volatile suboxide $\mathrm{SiO}$ by reaction between silicon and silica at the triple line. Dezellus et al. performed a dedicated study with $\mathrm{CuSi}$ alloys on silicon carbide substrates which had been deliberately oxidized to obtain oxide films a few tens of nanometers thick [10]. A typical wetting experiment consists of two steps (see Fig. 11): (1) Firstly, fast spreading is observed towards $100^{\circ}$, the equilibrium contact angle value of $\mathrm{Cu}-\mathrm{Si}$ alloy on bulk silica. Then, the contact angle remains constant during a time that depends on the initial silica film thickness. During this first step, deoxidation occurs close to the triple line, because in this particular area the distance between the liquid/solid interface (where the dissolution of silica takes place) and the liquid/vapour interface (where $\mathrm{SiO}$ evaporation occurs) is the smallest. (2) As soon as the liquid comes into contact with the true $\mathrm{SiC}$ surface, spreading occurs and the contact angle decreases toward the equilibrium contact angle on SiC. This second step is characterized by a constant triple line velocity and corresponds to reactive spreading limited by the kinetics of the dissolution reaction of the silica layer at the triple line. Note that when large pieces of SiC are brazed with Me-Si alloys, the deoxidation mechanism of the $\mathrm{SiC}$ surface by $\mathrm{SiO}$ formation gives the geometrical configuration a crucial role in alloy wetting, the difficulty increasing in the order: sessile drop $\rightarrow$ "capillary" brazing $\rightarrow$ "sandwich" brazing [18].

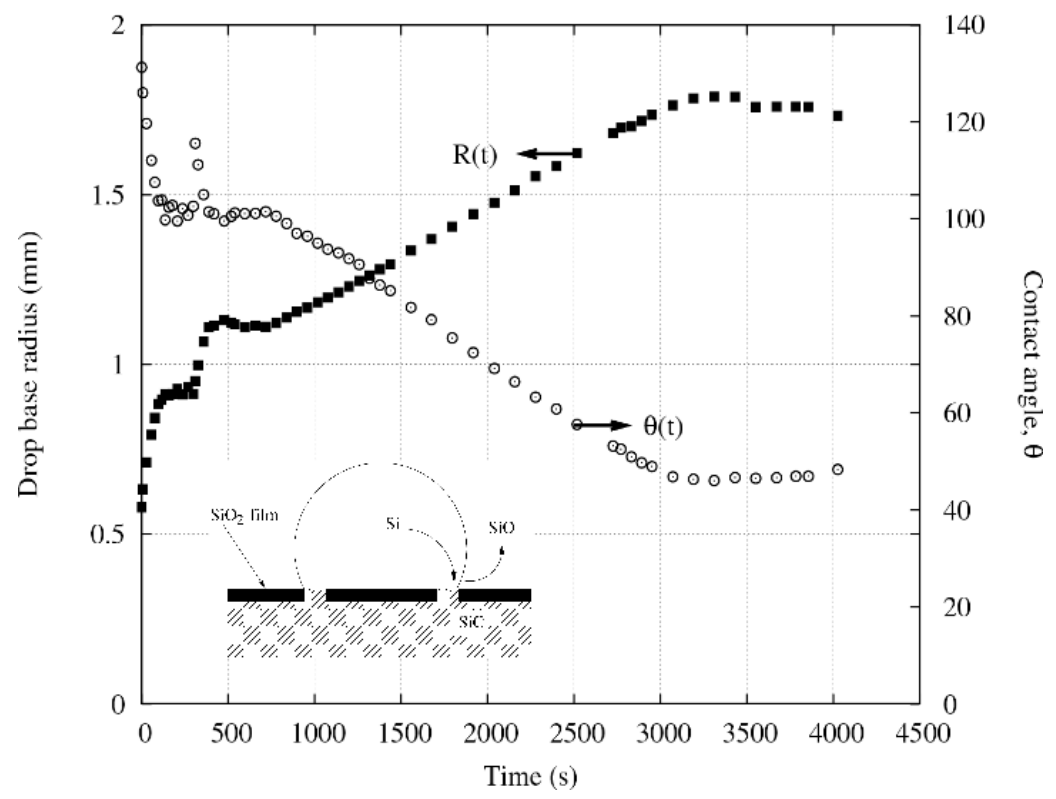

Fig. 11: Time-dependent variation in drop base radius $R$ and contact angle $\theta$ for $\mathrm{Cu}-40$ at.\% $\mathrm{Si}$ on the $\mathrm{C}$ face of an $\alpha$-SiC single crystal covered by a silica layer $60-70 \mathrm{~nm}$ thick [10]. 
At low temperatures normal metallic solids are covered by thin oxide films, a few nanometers thick, formed rapidly in contact with air at room temperature. Such oxides, that may be stable even in high vacuum or in low partial pressure of oxygen gas mixtures, are not wetted by liquid metals [14, 20, 31, 32]. Wetting can be strongly improved by reactions where intermetallic compounds are formed, leading to the replacement, in situ, of the oxidized surface by a clean surface of an intermetallic compound [32] (see Fig. 12). For this reason, as a general rule, the final degree of wetting in liquid metal/solid metal systems in which intense reactions occur at the interface is much less sensitive to environmental factors than in nonreactive systems.
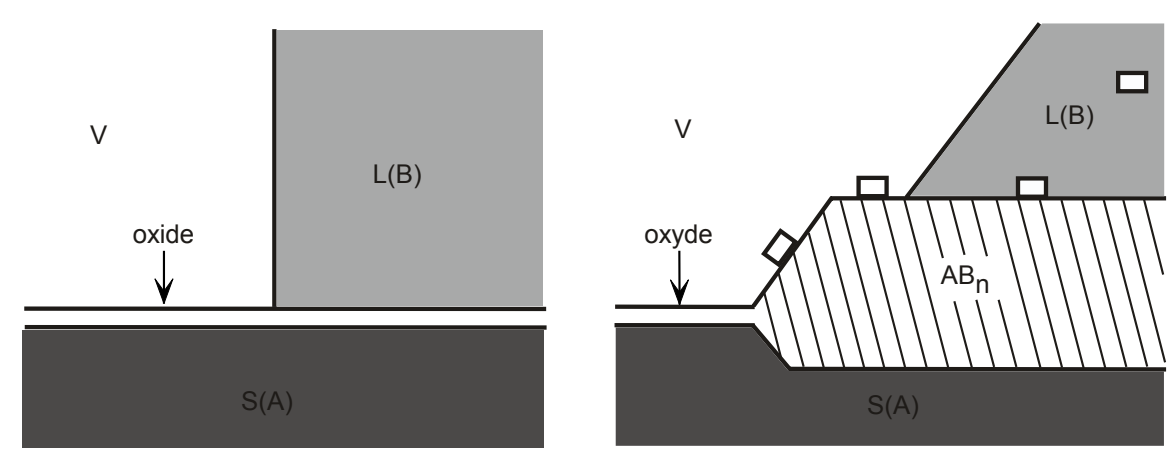

Fig. 12: Schematic description of the region close to the triple line for an oxidised metal (a) in the case of a non-reactive liquid metal B-solid metal A couple and (b) in the case of formation of a layer of intermetallic compound $\mathrm{AB}_{\mathrm{n}}$ at the interface [32].

\section{Conclusions}

Interfacial reactions leading to the formation of continuous layers of a new compound can improve wetting or conversely worsen it. This depends on the wettability by the liquid metal of the new compound compared to the wettability of the initial solid substrate. In some cases interfacial reactions can also improve wetting by removing wetting barriers (mainly oxide films) existing on otherwise wettable substrates surface. As for spreading kinetics in reactive metal /ceramic systems, a significant improvement in understanding and modelling this process has been achieved over the last ten years. Thus an analytical model was developed to describe spreading kinetics in systems with control by local reaction kinetics at the triple line. Moreover, the model proposed by Mortensen et al. for diffusion-controlled reactive spreading 
was improved to take into account the influence on spreading rate of the reaction occurring at the interface behind the triple line.

This review does not report on "dissolutive wetting". This is wetting accompanied by dissolution of the solid into the liquid with formation of a macroscopically non-planar solid/liquid interface $[14,40]$. Dissolutive wetting is a common process in liquid metal /solid metal systems but it is also relevant in some metal/ceramic systems such as $\mathrm{Ni} / \mathrm{C}$ [14], $\mathrm{Ni} / \mathrm{HfB}_{2}$ [28] and $\mathrm{AuNi} / \mathrm{ZrB}_{2}$ [39]. Although recent studies performed with model liquid metal/solid metal couples have contributed significantly to improving our knowledge of dissolutive wetting [21, 30, 40,41, 42] more work is needed to obtain a satisfactory description of the thermodynamics and kinetics of this type of wetting.

\section{REFERENCES}

[1] T.D. Blake. Wettability, chapter Dynamic Contact Angles and Wetting Kinetics, pages 251-310. Marcel Dekker, New York, 1993.

[2] V. Bougiouri, R. Voytovych, O. Dezellus, and N. Eustathopoulos (2007) Wetting and reactivity in $\mathrm{Ni}-\mathrm{Si} / \mathrm{C}$ system: experiments versus model predictions. Journal of Materials Science 42(6):2016-2023.

[3] N. Calderon, R. Voytovych, J. Narciso, and N. Eustathopoulos (in press) Wetting dynamics versus interfacial reactivity of AlSi alloys on carbon. Journal of Materials Science Doi: 10.1007/s10853-009-3909-6

[4] P. G. de Gennes. (1985) Wetting: statics and dynamics. Reviews of Modern Physics 57(3):827

[5] O. Dezellus. Contribution à l'étude des mécanismes de mouillage réactif. $\mathrm{PhD}$ thesis, INP-Grenoble (France), 2000.

[6] O. Dezellus and N. Eustathopoulos (1999) The role of van der waals interactions on wetting and adhesion in metal/carbon systems. Scripta Materialia 40(11):1283-1288.

[7] O. Dezellus, F. Hodaj, and N. Eustathopoulos (2002) Chemical reaction-limited spreading: the triple line velocity versus contact angle relation. Acta Materialia 50:4741-4753. [8] O. Dezellus, F. Hodaj, and N. Eustathopoulos (2003) Progress in modelling of chemical-reaction limited wetting. Journal of the European Ceramic Society 23(15):27972803.

[9] O. Dezellus, F. Hodaj, A. Mortensen, and N. Eustathopoulos (2001) Diffusion-limited reactive wetting. spreading of $\mathrm{Cu}-\mathrm{Sn}-\mathrm{Ti}$ alloys on vitreous carbon. Scripta Materialia 44:2543-2549. 
[10] O. Dezellus, F. Hodaj, C. Rado, J. N. Barbier, and N. Eustathopoulos (2002) Spreading of $\mathrm{Cu}-\mathrm{Si}$ alloys on oxidized $\mathrm{SiC}$ in vacuum: experimental results and modelling. Acta Materialia 50:979-991.

[11] O. Dezellus, R. Voytovych, A. Li, G. Constantin, F. Bosselet, and J. Viala (in press) Wettability of $\mathrm{Ti}_{3} \mathrm{SiC}_{2}$ by Ag-Cu and Ag-Cu-Ti melts. Journal of Materials Science Doi:10.1007/s10853-009-3941-6

[12] B. Drevet, R. Voytovych, R. Israel, and N. Eustathopoulos (2009) Wetting and adhesion of $\mathrm{Si}$ on $\mathrm{Si}_{3} \mathrm{~N}_{4}$ and $\mathrm{BN}$ substrates. Journal of the European Ceramic Society 29(11):2363-2367.

[13] N. Eustathopoulos (2005) Progress in understanding and modeling reactive wetting of metals on ceramics. Current Opinion in Solid State and Materials Science 9(4-5):152-160.

[14] N. Eustathopoulos, M.G. Nicholas, and B. Drevet. Wettability at High Temperatures. Pergamon Materials Series,vol 3, Pergamon, Oxford 1999.

[15] N. Frage, N. Froumin, and M. P. Dariel (2002) Wetting of TiC by non-reactive liquid metals. Acta Materialia 50(2):237-245.

[16] F. Hodaj, O. Dezellus, J. N. Barbier, A. Mortensen, and N. Eustathopoulos (2007) Diffusion-limited reactive wetting: effect of interfacial reaction behind the advancing triple line. Journal of Materials Science 42(19):8071-8082.

[17] S. Kalogeropoulou, C. Rado, and N. Eustathopoulos (1999) Mechanisms of reactive wetting: the wetting to non-wetting case. Scripta Materialia 41(7):723-728.

[18] A. Koltsov, F. Hodaj, and N. Eustathopoulos (2008) Brazing of AlN to Si by a Pr silicide: Physicochemical aspects. Materials Science and Engineering: A 495(1-2):259-264. [19] A. Koltsov, M. Dumont, F. Hodaj, and N. Eustathopoulos (2006) Influence of Ti on wetting of AlN by Ni-base alloys. Materials Science and Engineering: A 415(1-2):171-176. [20] O. Kozlova, R. Voytovych, M.-F. Devismes, and N. Eustathopoulos (2008) Wetting and brazing of stainless steels by copper-silver eutectic. Materials Science and Engineering: A 495(1-2):96-101.

[21] O. Kozlova, R. Voytovych, P. Protsenko, and N. Eustathopoulos (in press) Nonreactive versus dissolutive wetting of $\mathrm{Ag}-\mathrm{Cu}$ alloys on $\mathrm{Cu}$ substrates. Journal of Materials Science Doi: 10.1007/s10853-009-3924-7

[22] K. Landry and N. Eustathopoulos (1996) Dynamics of wetting in reactive metal/ceramic systems: linear spreading. Acta Materialia 44(10):3923-3932.

[23] A. Mortensen, B. Drevet, and N. Eustathopoulos(1997) Kinetics of diffusion-limited spreading of sessile drops in reactive wetting. Scripta Materialia 36(6):645-651. 
[24] M. L. Muolo, E. Ferrera, L. Morbelli, and A. Passerone (2004) Wetting, spreading and joining in the alumina-zirconia-Inconel 738 system. Scripta Materialia 50(3):325-330..

[25] Y. V. Naidich. Progress in Surface and Membrane Sciences, volume 14, chapter The Wettability of Solids by Liquid Metals, pages 353-484. Academic Press, New-York, 1981.

[26] Yu. V. Naidich, V. V. Zabuga, and V. M. Perevertailo (1992) Temperature dependence of spreading kinetics in systems with different types of interaction of contacting phases. Adgeziya Rasplavov i Paika Materialov 27:23-34.

[27] Y.V. Naidich and N.Y. Taranets. In N. Eustathopoulos, editor, Proc. Int. Conf. High Temperature Capillarity, page 138. Reproprint, Bratislava, 1995.

[28] A. Passerone, M. L. Muolo, F. Valenza, F. Monteverde, and N. Sobczak (2009) Wetting and interfacial phenomena in Ni-HfB2 systems. Acta Materialia 57(2):356-364.

[29] S.I. Popel, V.N. Kozhurkov, and T.V. Zaharova (1971) Zashchita Metall., 7:421.

[30] P. Protsenko, O. Kozlova, R. Voytovych, and N. Eustathopoulos (2008) Dissolutive wetting of Si by molten Cu. Journal of Materials Science 43(16):5669-5671.

[31] P. Protsenko, A. Terlain, M. Jeymond, and N. Eustathopoulos (2002) Wetting of Fe7.5Cr steel by molten $\mathrm{Pb}$ and $\mathrm{Pb}-17 \mathrm{Li}$. Journal of Nuclear Materials 307-311(Part 2):13961399.

[32] P. Protsenko, A. Terlain, V. Traskine, and N. Eustathopoulos (2001) The role of intermetallics in wetting in metallic systems. Scripta Materialia 45(12):1439-1445.

[33] C. Rado and N. Eustathopoulos (2004) The role of surface chemistry on spreading kinetics of molten silicides on silicon carbide. Interface Science 12(1):85-92.

[34] C. Rado, S. Kalogeropoulou, and N. Eustathopoulos (1999) Wetting and bonding of Ni-Si alloys on silicon carbide. Acta Materialia 47(2):461-473.

[35] C. Rado, S. Kalogeropoulou, and N. Eustathopoulos (2000) Bonding and wetting in non-reactive metal/SiC systems: weak or strong interfaces? Materials Science and Engineering A 276(1-2):195-202.

[36] E. Saiz, R. M. Cannon, and A. P. Tomsia (2000) Reactive spreading: adsorption, ridging and compound formation. Acta Materialia 48(18-19):4449-4462.

[37] E. Saiz and A. P. Tomsia. (2004) Atomic dynamics and Marangoni films during liquid-metal spreading. Nature Materials, 3(12):903-909.

[38] R. Voitovitch, A. Mortensen, F. Hodaj, and N. Eustathopoulos (1999) Diffusionlimited reactive wetting: study of spreading kinetics of $\mathrm{Cu}-\mathrm{Cr}$ alloys on carbon substrates. Acta Materialia 47(4):1117-1128. 
[39] R. Voytovych, A. Koltsov, F. Hodaj, and N. Eustathopoulos (2007) Reactive vs nonreactive wetting of $\mathrm{ZrB}_{2}$ by azeotropic Au-Ni. Acta Materialia 55(18):6316-6321.

[40] J. A. Warren, W. J. Boettinger, and A. R. Roosen (1998) Modeling reactive wetting. Acta Materialia 46(9):3247-3264.

[41] L. Yin, S. J. Meschter, and T. J. Singler (2004) Wetting in the Au-Sn system. Acta Materialia 52(10):2873-2888.

[42] L. Yin, B. T. Murray, and T. J. Singler (2008) Dissolutive wetting in the Bi-Sn system. Acta Materialia 54(13):3561-3574.

[43] M. Zaidi. PhD thesis, Ecole Centrale de Paris (France), 2008. 